\title{
MRI-Based Assessment of Masticatory Muscle Changes in TMD Patients After Whiplash Injury
}

Yeon-Hee Lee ( $\sim$ omod0209@gmail.com )

Kyung Hee University Dental Hospital

Kyung Mi Lee

Kyung Hee University College of Medicine

Q-Schick Auh

Kyung Hee University Dental Hospital

\section{Research Article}

Keywords: Whiplash injury; Temporomandibular disorder, Magnetic resonance imaging, Masticatory muscle, Lateral pterygoid muscle, Masseter muscle

Posted Date: March 12th, 2021

DOI: https://doi.org/10.21203/rs.3.rs-283243/v1

License: @ (i) This work is licensed under a Creative Commons Attribution 4.0 International License. Read Full License 


\section{Abstract \\ Objective}

To investigate the change in volume and signal in the masticatory muscles and temporomandibular joint (TMJ) of patients with temporomandibular disorder (TMD) after whiplash injury based on magnetic resonance imaging (MRI) and to correlate them with other clinical parameters.

\section{Methods}

Ninety patients ( 64 women, 26 men; mean age: $39.36 \pm 15.40$ years), including 45 patients with symptoms of TMD after whiplash injury (WTMD), and 45 age- and sex-matched controls with TMD due to idiopathic causes (iTMD) were included. TMD was diagnosed using the study diagnostic criteria for TMD Axis I, and MRI findings of the TMJ and masticatory muscles were investigated. To evaluate the severity of TMD pain and muscle tenderness, we used a visual analog scale (VAS), palpation index (PI), and neck PI.

\section{Results}

TMD indexes, including VAS, PI, and neck PI were significantly higher in the WTMD group. In the WTMD group, muscle tenderness was highest in the masseter muscle (71.1\%), and muscle tenderness in the temporalis (60.0\%), lateral pterygoid muscle (LPM) (22.2\%), and medial pterygoid muscle $(15.6 \%)$ was significantly more frequent than that in the iTMD group $($ all $p<0.05)$. The most noticeable structural changes in the masticatory muscles occurred in the LPM with whiplash injury. Volume $(57.8 \%$ vs. $17.8 \%)$ and signal changes $(42.2 \%$ vs. $15.6 \%)$ of LPM were significantly more frequent in the WTMD group than in the iTMD group. The presence of signal changes in the LPM was positively correlated with the increased VAS scores only in the WTMD group $(r=0.346, p=0.020)$. The prevalence of anterior disc displacement without reduction (ADDWoR) (53.3\% vs. $28.9 \%$ ) and disc deformity (57.8\% vs. $40.0 \%)$ were significantly higher in the WTMD group $(p<0.05)$. The presence of headache, sleep problems, and psychological distress was significantly higher in the wTMD group than in the iTMD group.

\section{Conclusion}

Abnormal MRI findings and their correlations with clinical characteristics of the WTMD group were different from those of the iTMD group. The underlying neuropathophysiology may differ depending on the cause of TMD, raising the need for a treatment strategy accordingly.

\section{Introduction}

Whiplash injury refers to a macrotrauma that occurs with a hyperextension of the head and neck vertebrae followed by hyperflexion when a sudden or excessive force is applied [1]. In road traffic accidents, injuries occur mainly due to side-impact or rear-end collisions [2, 3] (Fig. 1). Such cases present with a variety of clinical manifestations, including neck stiffness, neck pain disability, psychological distress, headache, and temporomandibular disorder (TMD) [4-6]. The incidence of TMD in patients with whiplash injury is low to moderate and ranges from $14-37.5 \%[7]$. It is important to note that patients commonly suffer from chronic whiplash injury and clinically have pain in a wider range of the body [8]. Approximately $40 \%$ of patients with whiplash injuries suffer from persistent pain and chronic disability.[9]

TMD is an umbrella term for pain and dysfunction in the temporomandibular joint (TMJ), masticatory muscles, and adjacent structures. Population-based studies showed that $60-70 \%$ of the general population has at least one sign of TMD, $12.1 \%$ have TMDrelated pain, and only $5 \%$ seek treatment $[10,11]$. Plausible risk factors for TMD, either alone or more likely in combination include macrotrauma, microtrauma, other body pain conditions, self-reported previous pain experience, and psychological status. The etiology of TMD moved from a mechanical-based phenomenon to a chronic pain biopsychosocial model [12]. Typical and frequent TMD symptoms include TMJ noise and pain, followed by restriction of mandibular movement, headache, neck pain, ear pain, and tinnitus. Whiplash injury is considered an initiating or aggravating factor of TMD. $[5,13]$ Thus, patients with TMD suffering from whiplash injury have wider and stronger pain than those with only microtrauma.

Page 2/20 
The neuropathology of TMD development and aggravation related to whiplash injury can be distinguished from other TMD etiologies. In general, pain in whiplash injury can occur as a result of direct trauma to the muscles, ligaments, and tendons, which may lead to substantial tissue damage [14]. TMD caused by the accumulation of microtrauma, such as parafunctional habits or malocclusion, occurs due to changes at the peripheral level. However, sudden large impact can be transmitted to the central nervous system (CNS) because of the occurrence of diffuse axonal injury throughout the injury [15]. Sometimes referral patterns may develop because of CNS involvement resulting from prolonged masticatory muscle pain, and the pain pattern in individuals becomes more complex. Additionally, experiences of emotional trauma from the injury that pose a potential threat to life can negatively impact personal future health and finances [16]. These physical and psychosocial risk factors create combined synergies and form complex neuropathologies of pain amplification in TMD.

Masticatory muscles are poorly understood in terms of posttraumatic sequelae. All four main masticatory muscles, including the masseter, temporalis, medial pterygoid muscle (MPM), and lateral pterygoid muscle (LPM), are attached to the mandible and govern the function to move the mandible (Fig. 2). The masseter and temporalis muscles on the outside of the jaw bones have been studied, and it has been reported that these muscles are commonly affected in patients with TMD [17]. The masseter is a jaw-closing muscle that elevates the mandible and is one of the strongest in the human body. The temporalis muscle enables elevation and retraction of the mandible. An important role of the MPM is the fine control and stabilization of the vertical mandibular position, concentrically activating jaw closing [18]. Among all four muscles of mastication, the LPM is the only muscle that depresses the mandible. Traumatic injury results in muscle pain, muscle wasting, skeletal demineralization, and disability [19]. However, there is limited information on the changes in the masticatory muscles of patients with TMD after whiplash injury.

Magnetic resonance imaging (MRI) is the gold standard for evaluating the abnormalities in the TMJ and masticatory muscles, and for determining the disc-condyle relationship. [6,13] Atrophy, fibrotic change, and fatty replacement of the masticatory muscle regularly occur with either disuse or denervation [20], which can occur as a consequence of immobilization or disuse after whiplash injury. On T1- and T2-weighted MRI images, masticatory muscles with myotonic dystrophy present as high signal intensity areas because of fatty replacement [21]. In addition, the huge tensile force throughout the whiplash injury exerted on a muscle may lead to excessive stretching of the muscle fibers and consequently a tear, and impair the muscle-tendon junction [22]. According to our previous MRIbased studies, patients with TMD due to whiplash injury suffered more distortion of the disc-condyle relationship and LPM changes $[6,13]$. TMJ disc displacement leads to degenerative changes in the disc deformity and condylar degeneration,[23] and the symptoms of TMD might become chronic. Until now, most MRI studies in patients with TMD evaluated intra-articular changes [24].

Thus, the present study aimed to investigate the relationship between changes in the masticatory muscles and TMJ on MRI and clinical pain intensity in patients with TMD due to whiplash injury, and to compare their clinical and MRI characteristics with those of patients with TMD due to idiopathic causes. We also investigated the factors that affect subjective pain intensity and whether these results differ between the TMD due to idiopathic causes (iTMD) and TMD after whiplash injury (WTMD) groups. Our hypotheses were as follows: (1) compared to the patients with ITMD, patients with WTMD will have higher pain intensity and more changes in the masticatory muscles, and have more tenderness upon palpation; (2) structural changes in the TMJ and masticatory muscles will be associated with a higher severity of TMD symptoms, and differences between the WTMD and iTMD groups can be observed. Our study is the first study to examine the changes in the four major masticatory muscles in patients with whiplash injury using MRI, and to determine which muscular factors increase discomfort and pain in patients with wTMD.

\section{Methods}

\section{Participants and demographic data}

The present study was carried out in accordance with the Declaration of Helsinki and approved by the Institutional Review Board (IRB) of the Kyung Hee University Dental Hospital. Informed consent was obtained from all patients.

This retrospective case-control study involved 45 randomly selected patients with wTMD and 45 randomly selected patients with iTMD, who were selected using a simple random sampling procedure employing a random number table. The " $w T M D$ " group $(n=45)$ included patients who had first-onset TMD after sustaining a whiplash injury; the "iTMD" group $(n=45)$ comprised patients who had presented with idiopathic or non-traumatic TMD symptoms without any history of head/neck trauma.

The patients were diagnosed with TMD using the research diagnostic criteria (RDC) for TMD axis I,[25, 26] and the experience of whiplash injury was judged according to the Quebec Task Force on Whiplash-Associated Disorders.[2] We identified the patients who

Page $3 / 20$ 
had TMD and retrospectively reviewed all MRIs of their TMJs and TMJ reports from March 2017 through 2020. The inclusion criteria were as follows: no history of neck pain prior to the whiplash injury, no treatment on the current TMD symptoms other than medication, and no history of direct trauma to the jaw before or during the accident-the patients had no history of a TMD prior to the present TMD episode. The exclusion criteria were serious injuries, such as facial fracture and unstable multiple traumas, previous injury, neurological disorder unrelated to the trauma, and musculoskeletal disorder predating injury, rheumatism, psychological problems, and pregnancy. To assess the impact of whiplash injury in terms of distribution of TMD signs and symptoms, and MRI findings, all variables were compared by group.

\section{MRI acquisition and analysis}

All 90 patients underwent MRI examination on bilateral TMJs and masticatory muscles. High-resolution MRI images were obtained on a 3T MRI system (Signa ${ }^{\text {TM }}$ Genesis, GE Healthcare, Chicago, IL, USA) with a 6-cm $\times 8-\mathrm{cm}$ diameter surface coil. MRI examination was dependent on the MR sequences and protocol of Kyung Hee University Medical Center, and the details has also been revealed in our previous studies [13, 27]: All scans involved sagittal oblique sections (section thickness, $3 \mathrm{~mm}$ or less,; field of view, 15-cm; matrix dimensions, $256 \times 224$ matrix) and spin-echo sagittal MR images were obtained on the axial localizer images. T1-weighted images (T1WIs) and T2-weighted images (T2WIs) were obtained using a 650/14 TR/TE sequence and 2,650/82 TR/TE sequence, respectively. The proton density images were obtained using a 2,650/82 TR/TE sequence.

TMJs and adjacent masticatory muscles were evaluated in both the sagittal and coronal planes (Figure 3 ) to determine the abnormalities in the TMJ and the alteration of each masticatory muscle. Two head and neck radiologists with at least 8 years of experience in their field and who were blinded to the patients' clinical information visually analyzed the MRI findings. After determining the existence of MRI abnormalities, the TMJ and masticatory muscle measurements were evaluated using the INFINITT PACS (INFINITT Corp., Seoul, Korea).

\section{Validation of MRI findings}

We investigated the presence of MRI abnormalities of the TMJ and masticatory muscles, including disc displacement, effusion, disc deformity, condylar degeneration, and volume changes (VCs) and signal changes (SCs) in the four masticatory muscles, including the masseter muscle, temporalis muscle, LPM, and MPM. The detailed procedure of validation has been described in our previous papers. $[6,13]$ The disc position in the oblique sagittal plane was determined in the closed and open-mouth positions. In addition, disc position was classified as anterior disc displacement with reduction (ADDWR) or without reduction (ADDWoR) (Figure 4). In the T1WI, T2WI, and proton density (PD) weighted images, each muscle was considered to have an SC when the fatty replacement tissue accompanying the high intensity signal was observed widely across the muscle. In the same images, it was considered to have a VC when the masticatory muscle had decreased volume and fibrosis. To determine whether the difference between the measurements was statistically significant, the values of the masticatory muscles acquired in each MRI sequence on the right and left sides of the same patient were compared.

\section{Validation of clinical signs and symptoms of TMD}

\section{Contributing factors}

We investigated self-reported parafunctional activities using the Oral Behavior Checklist, which includes jaw-related behaviors, such as teeth clenching and bruxism.[28] Self-reported headache was evaluated using the dichotomous question "Do you have any headaches associated with TMD?" Self-assessment of tinnitus, psychological distress, and sleep problems was also reported. Each parameter was recorded as a binary answer (yes/no) in all patients.

\section{Characteristics of pain}

The duration of pain derived from the TMJ and adjacent structures was reported in days. Temporomandibular pain was scored by the patients subjectively, ranging from 0 (no pain at all) to 10 (the worst pain imaginable) using the visual analog scale (VAS).

\section{Palpation index $(\mathrm{PI})$ and neck PI}

$\mathrm{PI}$ is a reliable scoring system that analyzes the severity of myofascial pain, allowing TMD symptoms to be objectively evaluated. In each patient, we palpated 20 intra- and extraoral muscle sites and three sites in the neck. The index-finger palpation pressure was 1 
$\mathrm{kg} / \mathrm{cm}^{2}$ and was applied for $5 \mathrm{~s}$, as recommended in previous studies.[29, 30] To calibrate palpation pressures, we regularly pre-tested our index-finger pressure using a hand-held pressure algometer. For each site, a binary answer (yes/no) was provided. To calculate the PI score, we added all the positive answers and divided the sum by the number of events.[31] To further investigate the intensity of neck pain, we calculated the neck $\mathrm{Pl}$, which was defined as the number of positive responses to the palpation of neck muscles, including the sternocleidomastoid, splenius capitis, and trapezius muscles, divided by the number of events. Using these two indexes, we quantified clinical myofascial pain.

\section{Statistical methods}

For all discrete variables, the absolute and relative percentage distributions were calculated. Continuous variables are presented as means and standard deviations. Various statistical methods were used for data analysis. Using the Mann-Whitney U test, we examined the difference in the means of the continuous variables between the WTMD and ITMD groups. Chi-square and Fisher's exact tests were used to calculate the proportional equivalence of discrete variables, such as the presence of MRI abnormalities (\%) and patient's "yes" (\%) response describing TMD contributing factors. Through Spearman's correlation analysis, we examined the MRI findings that were correlated with a significant increase in each TMD index score. A $p<0.05$ level was set to be statistically significant. Data were analyzed using the Statistical Package for the Social Sciences for Windows version 25.0 (IBM Corp., Armonk, NY, USA).

\section{Results}

\section{Demographic patient characteristics}

Data from 45 patients with wTMD (mean age: $37.94 \pm 12.27$ ) and 45 patients with iTMD (mean age: $40.77 \pm 18.02$ years) were analyzed and compared. Among the patients with TMD who visited the hospital during the study period, female predominance (female:male $=2.45: 1$ ) was observed, and this sex ratio was reflected in both the WTMD (female: 68.9\%) and iTMD groups (female: $73.3 \%)$. In addition, the mean symptom duration of WTMD ( $66.27 \pm 58.06$ days) was not different from that of iTMD (57.78 \pm 48.33 days) $(p=0.453)$.

\section{Analysis of pain intensity}

The mean VAS score in the WTMD group was significantly higher than that in the iTMD group $(6.73 \pm 1.84$ vs. $4.32 \pm 2.80, p<0.001)$. Interestingly, TMD indexes, including PI and neck PI, were significantly higher in the WTMD group than in the iTMD group (Table 1). That is, the mean $\mathrm{PI}(0.27 \pm 0.21$ vs. $0.16 \pm 0.18, p<0.01)$ and neck $\mathrm{PI}(0.45 \pm 0.31$ vs. $0.27 \pm 0.23, p<0.01)$ scores in the wTMD group were significantly higher than that in the iTMD group.

\section{Clinical characteristics in WTMD and iTMD groups}

Table 2 shows the putative contributing factors and clinical symptoms of TMD in each group. The distributions of clenching habits, headache, sleep problems, and psychological distress in the WTMD group were different from those in the iTMD group. Specifically, the patients with wTMD were more likely to have headache ( $71.1 \%$ vs. $40.0 \%)$ and sleep problems $(57.8 \%$ vs. $35.6 \%)$, and psychological distress (33.3\% vs. $13.3 \%$ ), whereas clenching habits ( $8.9 \%$ vs. $26.7 \%$ ) were less common in the wTMD group (all p<0.05). The distributions of bruxism and tinnitus in the WTMD group were different from those in the iTMD group.

\section{Distribution of MRI Findings}

The distributions of MRI variables on the TMJ (Table 3) and masticatory muscles (Table 4) were significantly different between the WTMD and iTMD groups. Interestingly, patients with wTMD were more likely to have ADDWoR (53.3\% vs. $28.9 \%)$ and disc deformity (64.4\% vs. 33.3\%), which were significantly higher than those in the iTMD group (all $p<0.05$ ). The distributions of effusion, ADDWR, and condylar degeneration in the WTMD group were not significantly different from those in the iTMD group. The most prominent abnormal MRI finding in the WTMD group was disc deformity (64.4\%), followed by condylar degeneration (57.8\%), ADDWoR (53.3\%), ADDWR (24.4\%), and effusion (22.2\%) (Figure 5).

Regarding the masticatory muscles, the structural change in LPM was the most frequent change among the four major masticatory muscles in both groups (Figure 6). Specifically, both VC ( $57.8 \%$ vs. $17.8 \%)$ and SC ( $42.2 \%$ vs. $15.6 \%)$ of the LPM were significantly more prevalent in the WTMD group than in the iTMD group (all p<0.05). In contrast, VC ( $2.2 \%$ vs. $2.2 \%)$ and SC $(2.2 \%$ vs. $2.2 \%)$ of the temporalis muscle were very rare in both groups. In addition, changes in MPM were not observed in any case in the wTMD group, and 
both VC and SC were observed in only two patients (4.4\%) in the iTMD group. The structural changes in the masseter muscle on MRI were not observed in any case $(0.0 \%)$ in either group (Figure 7$)$.

\section{Distribution of muscle tenderness}

The distributions of muscle tenderness on palpation test were significantly different between the groups in the temporalis muscle, LPM, and MPM except for the masseter muscle (Table 5). Muscle tenderness was significantly higher in the temporalis muscle (60.0\% vs. $35.6 \%)$, LPM (22.2\% vs. $2.2 \%)$, and MPM (15.6\% vs. $0.0 \%$ ) in the wTMD group than in the iTMD group (all p < 0.05$)$. On the other hand, tenderness was most frequently observed in the masseter muscle in both wTMD (71.1\%) and iTMD (64.4\%) groups. In contrast to the remarkable frequent observations of actual structural changes in the LPM observed on MRI, muscle tenderness of the LPM was scarcely observed in the iTMD group (2.2\%) and only in $22.2 \%$ of patients in the WTMD group.

\section{Associated MRI findings with increasing TMD index}

VAS, which represents the degree of subjective pain, was positively correlated with masticatory muscle changes in wTMD, and with internal derangement of the TMJ in iTMD. Specifically, the presence of signal changes in the LPM was positively correlated with the increased VAS scores only in the WTMD group $(r=0.346, p=0.020)$. In contrast, the presence of ADDWoR ( $r=0.325, p=0.029)$ and condylar degeneration ( $r=0.297, p=0.047)$ was positively correlated with the increase in VAS scores in the iTMD group. In the iTMD group, the VAS score was moderately positively correlated with $\mathrm{PI}(r=0.300, p=0.045)$ and neck $\mathrm{PI}(r=0.301, p=0.044)$, and these correlations were not observed in the WTMD group. Regarding PI and neck PI scores, there were no significant MRI variables that were correlated. However, neck PI and PI were strongly positively correlated with each other in both the wTMD ( $r=0.866, p<0.001)$ and iTMD ( $r=0.764, p<0.001)$ groups (Table 6).

\section{Diagnostic classification of pain-related TMD}

Depending on the cause of TMD pain, the most common pain-related diagnostic criteria for TMD fall into two categories: muscular and joint pain. Pain of muscular origin includes subcategories of myofascial pain and myofascial pain with limited mouth opening. On the other hand, pain of joint origin means arthralgia. In this study, the TMD diagnosis was established according to RDC/TMD, and TMD was diagnosed into three subgroups [26]: pain of muscle origin, pain of joint origin, and mixed type. Because $93 \%$ of patients with WTMD and $89 \%$ of iTMDs were diagnosed with TMD with mixed muscle and joint pain, the data were not analyzed based on subgroups.

\section{Discussion}

Whiplash, a unique type of microtrauma mainly occurring in vehicle collisions, is caused by sudden dynamics of hyperextensionhyperflexion on the cervical spine. [32] Among the patients with whiplash injury, approximately $23 \%$ suffered chronic pain and disabilities. [33] Thus, it lowers the patient's quality of life and increases health costs. Neck pain and stiffness, and headache are the most prominent symptoms in whiplash injury [6]. Recently, a possible association between whiplash injury and TMD has been studied. Carroll et al. reported that TMD was more prevalent in individuals with whiplash injury (15.8\%) than in those without (4.7\%) [34]. Conversely, the prevalence of whiplash injury in populations with TMD (median 35\%) is higher than that in control groups without TMD (1.7-13\%).[5] Although there is limited information on the neuropathophysiologies of TMD development and aggravation after whiplash injury, research to explore this is ongoing. As hypothesized, many of the clinical symptoms and MRI findings of masticatory muscles of whiplash-related TMD can be distinguished from those of TMD resulting from an unknown cause.

One of our main findings was that patients with wTMD had higher pain intensity across wider jaw and neck areas compared to those with iTMD. This was consistent with previous results that patients with whiplash injury report higher pain scores and larger areas of local and referred pain than healthy controls [35]. The increased clinical pain observed in the wTMD group may be due to impaired diffuse noxious inhibitory controls (DNICs), a measure of central nervous system pain inhibition[36]. Moreover, sleep disturbance is related to decreased DNICs in patients with TMD [37]. Reduced reactivity of the hypothalamic-pituitary adrenal (HPA) axis has been associated with chronic widespread body pain [38]. Furthermore, thalamic activity also contributes significantly to the pain processing. Decreased thalamic activity can cause exaggerated pain following innocuous peripheral stimulation [39]. Collectively, changes to the process of central endogenous pain inhibition through interference with DNICs, HPA axis, or thalamic activity can occur in patients with whiplash-related TMD, and pain is more likely to be amplified and prolonged in such patients. 
Widespread pain, which is not limited to the injured area and increased pain intensity, is derived from the dynamics of the nociceptive pathway at the CNS level. Hypersensitivity after whiplash injury occurs both locally, i.e., throughout the neck area, and at more distant sites beyond the boundary of the damaged peripheral nerve [40]. Thus, deep tissue is damaged in the cervical joint by direct application of shear force, compression, and excessive stretching through whiplash injury, but it can also affect the TMJ area. Pain wind-up refers to the phenomenon of increased excitability of CNS induced by frequency-dependent electrical stimulation of afferent C-fibers [41]. Pain wind-up can also be a mechanism of hypersensitivity and in whiplash-associated TMD. There were clear experimental results showing that patients with painful TMD have reduced pain thresholds and sensory impairment after innoxious stimuli [40]. Interestingly, central hypersensitivity is not only specific to whiplash injury, even though this phenomenon is seen in a variety of chronic pain syndromes [40,42]. Similar neuropathology may underlie a variety of chronic pain, including TMD, and further investigation is required on how it serves in detail.

Regarding MRI findings on TMJ, more than $50 \%$ of patients with WTMD had ADDWoR and condylar degeneration, and were significantly more prevalent than those with iTMD. In general, the TMJ is the most affected structure from TMD [43]. To the best of our knowledge, only a few MRI studies have validated the signs and symptoms of whiplash injury-induced TMD. During sudden macrotrauma, abrupt changes in the position of the mandible and TMJ disc followed by TMJ-ligament elongation and TMJ disc displacement may occur.[44] In a previous MRI study, displacement (56\%) and abnormal joint fluid or edema (65\%) of the TMJ were observed in the patients who had TMD after sustaining whiplash injury [45]. In addition, proper disc positioning is a prerequisite for normal movement of the mandibular condyle. Disc displacement progresses from reducible to non-reducible, and ADDWoR and condylar degeneration can be associated with each other [46]. Abnormal positioning of the articular disc may cause closed lock jaw position, which evokes TMJ clicking and pain, as well as limits jaw function [47]. Interestingly, the VAS score was positively related with ADDWoR and disc deformity only in iTMD, and this correlation was not observed in WTMD.

Our main MRI finding was that patients with WTMD had remarkable structural changes in the LPM. Substantial structural change in the LPM may have been observed considerably more frequently in WTMD than in ITMD because LPM is more susceptible to whiplash injury than other masticatory muscles. Additionally, LPM is a direct major factor in the occurrence of whiplash injury-related TMD. The LPM controls the rotation and translation of the disc and condyle, protrudes the mandible, and stabilizes the articular disc [48]. LPM plays a somewhat secondary role in mastication, but it is directly related to changes in the mandibular condyle and disc. Pathologic changes in the LPM can be associated with TMJ disc displacement $[49,50]$. Recent MRI results have shown structural muscle changes in the form of reduced muscle volume, fatty infiltration, and muscle atrophy in patients with whiplash-related disorders. [51, 52] In our previous LPM-related MRI study, significant positive correlations were reported between structural changes in the LPM, ADDWoR, disc deformity, and condylar degeneration in patients with TMD after whiplash injury[6]. Furthermore, rapid LPM stretching induces reflex contracture with disc displacement, resulting in pain [6,53]. On the contrary, no muscle changes were observed in asymptomatic individuals or individuals with idiopathic or non-traumatic neck pain [51]. We found that the VAS score was correlated with the structural changes of LPM only in WTMD.

Among and/or within the human masticatory muscles, many anatomical differences exist, indicating that different muscles are specialized for their resistance against whiplash injury. In our results, more than $60 \%$ of patients with wTMD had muscle tenderness in the masseter and temporalis muscles. Architecturally, the masseter and temporalis muscles can deliver higher forces than the pterygoid muscles. Thus, masseter and temporalis muscles play a more crucial role in mastication, which can lead to fatigue build-up and become vulnerable to tenderness [54]. In addition, the average thickness values of the masseter muscle (13.65 $\pm 2.19 \mathrm{~mm})$, temporalis muscle $(6.66 \pm 1.14 \mathrm{~mm})$, MPM $(14.73 \pm 1.32 \mathrm{~mm})$, and LPM $(15.59 \pm 1.40 \mathrm{~mm})$ were different [55-57]. Specialization in fiber type composition and fiber cross-sectional area can be reflected in these intramuscular differences. Compared to the masseter and pterygoid muscles, the temporalis has significantly larger fibers and a notably different fiber type composition [58]. Furthermore, the myosin heavy chain $(\mathrm{MyHC})$ content of muscle fibers mainly determines their force-velocity properties [59]. A regionally higher proportion of MyHC type I, expressed in slow muscle fibers, was found in the anterior temporalis, deep masseter, and anterior MPM. [60]. However, a previous study showed that MyHC type and isoform composition do not sufficiently explain the difference between the form and function of the muscles [61]. Further research is needed to reach a clearer conclusion about the impact of whiplash-related TMD on each masticatory muscle.

Finally, we observed that headache, sleep problems, and psychological distress were significantly more prevalent in the wTMD group than in the iTMD group. We must focus on the fact that CNS-related factors were more prevalent in the WTMD group. Headache and sleep problems possibly co-occur from the result of the dysregulation of shared brain regions, such as the trigeminal nucleus caudalis and thalamus [62]. Sleep problems deleteriously affect central pain modulatory systems [37]. Headache has been suggested as an

Page $7 / 20$ 
aggravating and potential risk factor for TMD symptoms [63]. Psychological distress is often accompanied by CNS-level symptoms, and is associated with more pain and disability in whiplash injury [42]. In addition, psychological factors, along with physical factors, can play a role in the progress or recovery from whiplash injury [64]. This suggests that neuropathophysiologies of wTMD may differ from that of $\mathrm{TTMD}$, and that TMD should be understood in a biopsychosocial model considering macrotrauma. The interconnectivity between biological factors and psychological factors can involve the development, processing, and chronicity of whiplash-related TMD symptoms. Furthermore, we need to have specific coping and treatment strategies for patients with wTMD.

This study has several limitations. In our study, we only checked for the presence of self-reported psychological distress, not through elaborate questionnaires or diagnostic tests. To understand whiplash injury-related TMD in the biopsychosocial model, further systematic investigation of the psychological aspects of patients will be required. Axis II of the DC/TMD or RDC/TMD diagnostic tool might be helpful in examining psychosocial factors. $[65,66]$ In addition, this study has the advantage that it had a randomized controlled design, but a large-scale population-based study is needed to avoid bias due to data composition and to reach a more general conclusion. Because the masticatory muscles function cooperatively and elaborately during jaw movement,[67] the pathological changes in one masticatory muscle will ultimately affect other muscle pathologies. Therefore, it is necessary to further study the differences before and after whiplash injury of each muscle over a long period of observation, and the relationships among the masticatory muscles.

\section{Conclusions}

We investigated and analyzed the clinical and MRI findings of patients with TMD caused by whiplash injury, and compared the results of patients with idiopathic causes to TMD. This is the first study to comprehensively investigate the four major masticatory muscles after whiplash injury using MRI, and their correlation with clinical TMD indexes. We suggest that patients with TMD who have whiplash macrotrauma can have different neurophysiological responses and pain control mechanisms than those with idiopathic causes. Although consistent results for drawing a general conclusion are limited, we hope our results can help in understanding the clinical symptoms and neuropathophysiology of whiplash-related TMD, and provide information for the appropriate wTMD-specific treatment strategy.

\section{Declarations}

\section{Data Availability Statement}

The datasets generated and/or analyzed during this study are available from the corresponding author upon reasonable request. Because patient consent is required for data disclosure, we may disclose data conditionally through internal discussion and the Institutional Review Board (IRB) of the Kyung Hee University Dental Hospital.

Ethics approval and consent to participate: The research protocol was reviewed in compliance with the Helsinki Declaration and approved by the Institutional Review Board of the Kyung Hee University Dental Hospital. Written informed consent was obtained from all individual participants.

Authors' contributions: Y.-H.L. wrote the paper. Y.-H.L. and Q.-S.A contributed to data acquisition, Y.-H.L. and K.-M.L. for both data analysis and interpretation. Y.-H.L., and K.-M.L. provided their expertise and contributed to the figures. Y.-H.L. provided her expertise and contributed to the revisions. All authors have read and agreed to the published version of the manuscript.

Acknowledgments: None.

Conflicts of Interest: The authors declare no conflicts of interest.

Funding: This research was supported by the National Research Foundation of Korea (NRF) Grant funded by the Korean government (MIST) (No. NRF 2020R1F1A1070072 obtained by Y.-H.L.).

Availability of data and materials: If there are people requesting data from this study, data can be disclosed in cases upon obtaining KHU_IRB approval.

\section{References}


1. Haggman-Henrikson B, Lampa E, Marklund S, Wanman A: Pain and Disability in the Jaw and Neck Region following Whiplash Trauma. Journal of dental research 2016, 95(10):1155-1160.

2. Spitzer WO, Skovron ML, Salmi LR, Cassidy JD, Duranceau J, Suissa S, Zeiss E: Scientific monograph of the Quebec Task Force on Whiplash-Associated Disorders: redefining "whiplash" and its management. Spine (Phila Pa 1976) 1995, 20(8 Suppl):1s-73s.

3. Yadla S, Ratliff JK, Harrop JS: Whiplash: diagnosis, treatment, and associated injuries. Current reviews in musculoskeletal medicine 2008, 1(1):65-68.

4. Fernandez CE, Amiri A, Jaime J, Delaney P: The relationship of whiplash injury and temporomandibular disorders: a narrative literature review0. Journal of Chiropractic Medicine 2009, 8(4):171-186.

5. Haggman-Henrikson B, Rezvani M, List T: Prevalence of whiplash trauma in TMD patients: a systematic review. Journal of oral rehabilitation 2014, 41(1):59-68.

6. Lee YH, Lee KM, Auh QS, Hong JP: Magnetic Resonance Imaging-Based Prediction of the Relationship between Whiplash Injury and Temporomandibular Disorders. Front Neurol 2017, 8:725.

7. Fernandez CE, Amiri A, Jaime J, Delaney P: The relationship of whiplash injury and temporomandibular disorders: a narrative literature review. J Chiropr Med 2009, 8(4):171-186.

8. Myrtveit SM, Skogen JC, Sivertsen B, Steingrímsdóttir ÓA, Stubhaug A, Nielsen CS: Pain and pain tolerance in whiplash-associated disorders: A population-based study. Eur J Pain 2016, 20(6):949-958.

9. Barnsley L, Lord S, Bogduk N: Whiplash injury. Pain 1994, 58(3):283-307.

10. Von Korff M, Le Resche L, Dworkin SF: First onset of common pain symptoms: a prospective study of depression as a risk factor. Pain 1993, 55(2):251-258.

11. Lim PF, Smith S, Bhalang K, Slade GD, Maixner W: Development of temporomandibular disorders is associated with greater bodily pain experience. Clin J Pain 2010, 26(2):116-120.

12. Skármeta NP, Pesce MC, Saldivia J, Espinoza-Mellado P, Montini F, Sotomayor C: Changes in understanding of painful temporomandibular disorders: the history of a transformation. Quintessence Int 2019, 50(8):662-669.

13. Lee YH, Lee KM, Auh QS, Hong JP: Sex-related differences in symptoms of temporomandibular disorders and structural changes in the lateral pterygoid muscle after whiplash injury. J Oral Rehabil 2019, 46(12):1107-1120.

14. Curatolo M, Bogduk N, Ivancic PC, McLean SA, Siegmund GP, Winkelstein BA: The role of tissue damage in whiplash-associated disorders: discussion paper 1. Spine (Phila Pa 1976) 2011, 36(25 Suppl):S309-S315.

15. McKee AC, Daneshvar DH: The neuropathology of traumatic brain injury. Handb Clin Neurol 2015, 127:45-66.

16. Sareen J: Posttraumatic stress disorder in adults: impact, comorbidity, risk factors, and treatment. Can J Psychiatry 2014, 59(9):460-467.

17. Vedana L, Landulpho AB, Andrade e Silva F, Buarque e Silva WA: Electromyographic evaluation during masticatory function, in patients with temporomandibular disorders following interocclusal appliance treatment. Electromyogr Clin Neurophysio/ 2010, 50(1):33-38.

18. Chen $\mathrm{H}$, Whittle T, Gal JA, Murray GM, Klineberg IJ: The medial pterygoid muscle: a stabiliser of horizontal jaw movement. J Oral Rehabil 2017, 44(10):779-790.

19. Schellhas KP: MR imaging of muscles of mastication. American Journal of Roentgenology 1989, 153(4):847-855.

20. Hamrick MW, McGee-Lawrence ME, Frechette DM: Fatty Infiltration of Skeletal Muscle: Mechanisms and Comparisons with Bone Marrow Adiposity. Front Endocrinol (Lausanne) 2016, 7:69-69.

21. Zanoteli E, Yamashita HK, Suzuki H, Oliveira AS, Gabbai AA: Temporomandibular joint and masticatory muscle involvement in myotonic dystrophy: a study by magnetic resonance imaging. Oral Surg Oral Med Oral Pathol Oral Radiol Endod 2002, 94(2):262271.

22. Fernandes TL, Pedrinelli A, Hernandez AJ: MUSCLE INJURY - PHYSIOPATHOLOGY, DIAGNOSIS, TREATMENT AND CLINICAL PRESENTATION. Rev Bras Ortop 2011, 46(3):247-255.

23. Taskaya-Yilmaz N, Ogutcen-Toller M: Magnetic resonance imaging evaluation of temporomandibular joint disc deformities in relation to type of disc displacement. Journal of oral and maxillofacial surgery: official journal of the American Association of Oral and Maxillofacial Surgeons 2001, 59(8):860-865; discussion 865-866. 
24. Ariji Y, Ariji E: Magnetic resonance and sonographic imagings of masticatory muscle myalgia in temporomandibular disorder patients. Jpn Dent Sci Rev 2017, 53(1):11-17.

25. Dworkin SF: Research Diagnostic criteria for Temporomandibular Disorders: current status \& future relevance. Journal of oral rehabilitation 2010, 37(10):734-743.

26. Truelove E, Pan W, Look JO, Mancl LA, Ohrbach RK, Velly AM, Huggins KH, Lenton P, Shiffman EL: The Research Diagnostic Criteria for Temporomandibular Disorders. IIl: validity of Axis I diagnoses. Journal of orofacial pain 2010, 24(1):35-47.

27. Lee Y-H, Lee KM, Auh QS, Hong J-P: Magnetic Resonance Imaging-Based Prediction of the Relationship between Whiplash Injury and Temporomandibular Disorders. Front Neurol 2018, 8:725-725.

28. Markiewicz MR, Ohrbach R, McCall WD, Jr.: Oral behaviors checklist: reliability of performance in targeted waking-state behaviors. Journal of orofacial pain 2006, 20(4):306-316.

29. Goulet JP, Clark GT, Flack VF: Reproducibility of examiner performance for muscle and joint palpation in the temporomandibular system following training and calibration. Community dentistry and oral epidemiology 1993, 21(2):72-77.

30. Schiffman E, Ohrbach R, Truelove E, Look J, Anderson G, Goulet J-P, List T, Svensson P, Gonzalez Y, Lobbezoo F et al: Diagnostic Criteria for Temporomandibular Disorders (DC/TMD) for Clinical and Research Applications: recommendations of the International RDC/TMD Consortium Network* and Orofacial Pain Special Interest Groupt. Journal of oral \& facial pain and headache 2014, 28(1):6-27.

31. da Cunha SC, Nogueira RV, Duarte AP, Vasconcelos BC, Almeida Rde A: Analysis of helkimo and craniomandibular indexes for temporomandibular disorder diagnosis on rheumatoid arthritis patients. Braz J Otorhinolaryngo/ 2007, 73(1):19-26.

32. Cote P, Cassidy JD, Carroll L, Frank JW, Bombardier C: A systematic review of the prognosis of acute whiplash and a new conceptual framework to synthesize the literature. Spine (Phila Pa 1976) 2001, 26(19):E445-458.

33. Haggman-Henrikson B, List T, Westergren HT, Axelsson SH: Temporomandibular disorder pain after whiplash trauma: a systematic review. Journal of orofacial pain 2013, 27(3):217-226.

34. Carroll LJ, Ferrari R, Cassidy JD: Reduced or painful jaw movement after collision-related injuries: a population-based study. J Am Dent Assoc 2007, 138(1):86-93.

35. Johansen MK, Graven-Nielsen T, Olesen AS, Arendt-Nielsen L: Generalised muscular hyperalgesia in chronic whiplash syndrome. PAIN 1999, 83(2).

36. Pereira-Silva R, Costa-Pereira JT, Alonso R, Serrão P, Martins I, Neto FL: Attenuation of the Diffuse Noxious Inhibitory Controls in Chronic Joint Inflammatory Pain Is Accompanied by Anxiodepressive-Like Behaviors and Impairment of the Descending Noradrenergic Modulation. Int J Mol Sci 2020, 21(8).

37. Edwards RR, Grace E, Peterson S, Klick B, Haythornthwaite JA, Smith MT: Sleep continuity and architecture: associations with paininhibitory processes in patients with temporomandibular joint disorder. Eur J Pain 2009, 13(10):1043-1047.

38. Generaal E, Vogelzangs N, Macfarlane GJ, Geenen R, Smit JH, Penninx BW, Dekker J: Reduced hypothalamic-pituitary-adrenal axis activity in chronic multi-site musculoskeletal pain: partly masked by depressive and anxiety disorders. BMC Musculoskelet Disord 2014, 15:227.

39. Burstein R, Jakubowski M, Garcia-Nicas E, Kainz V, Bajwa Z, Hargreaves R, Becerra L, Borsook D: Thalamic sensitization transforms localized pain into widespread allodynia. Ann Neurol 2010, 68(1):81-91.

40. Sterling M, Jull G, Vicenzino B, Kenardy J: Sensory hypersensitivity occurs soon after whiplash injury and is associated with poor recovery. Pain 2003, 104(3):509-517.

41. Herrero JF, Laird JM, López-García JA: Wind-up of spinal cord neurones and pain sensation: much ado about something? Prog Neurobiol 2000, 61(2):169-203.

42. Sterling M: Whiplash-associated disorder: musculoskeletal pain and related clinical findings. J Man Manip Ther 2011, 19(4):194200.

43. Suvinen $\mathrm{TI}$, Kemppainen P: Review of clinical EMG studies related to muscle and occlusal factors in healthy and TMD subjects. $J$ Oral Rehabil 2007, 34(9):631-644.

44. Boniver R: Temporomandibular joint dysfunction in whiplash injuries: association with tinnitus and vertigo. The international tinnitus journal 2002, 8(2):129-131

45. Pressman BD, Shellock FG, Schames J, Schames M: MR imaging of temporomandibular joint abnormalities associated with cervical hyperextension/hyperflexion (whiplash) injuries. J Magn Reson Imaging 1992, 2(5):569-574. 
46. Honda K, Natsumi Y, Urade M: Correlation between MRI evidence of degenerative condylar surface changes, induction of articular disc displacement and pathological joint sounds in the temporomandibular joint. Gerodontology 2008, 25(4):251-257.

47. Okeson JP: Joint intracapsular disorders: diagnostic and nonsurgical management considerations. Dent Clin North Am 2007, 51(1):85-103, vi.

48. Eriksson PO, Eriksson A, Ringqvist M, Thornell LE: Special histochemical muscle-fibre characteristics of the human lateral pterygoid muscle. Archives of oral biology 1981, 26(6):495-507.

49. Finden SG, Enochs WS, Rao VM: Pathologic changes of the lateral pterygoid muscle in patients with derangement of the temporomandibular joint disk: objective measures at MR imaging. AJNR American journal of neuroradiology 2007, 28(8):15371539.

50. Imanimoghaddam M, Madani AS, Hashemi EM: The evaluation of lateral pterygoid muscle pathologic changes and insertion patterns in temporomandibular joints with or without disc displacement using magnetic resonance imaging. International journal of oral and maxillofacial surgery 2013, 42(9):1116-1120.

51. Elliott JM, O'Leary S, Sterling M, Hendrikz J, Pedler A, Jull G: Magnetic resonance imaging findings of fatty infiltrate in the cervical flexors in chronic whiplash. Spine 2010, 35(9):948-954.

52. Uthaikhup S, Assapun J, Kothan S, Watcharasaksilp K, Elliott JM: Structural changes of the cervical muscles in elder women with cervicogenic headache. Musculoskeletal science \& practice 2017, 29:1-6.

53. Howard RP, Benedict JV, Raddin JH, Jr., Smith HL: Assessing neck extension-flexion as a basis for temporomandibular joint dysfunction. Journal of oral and maxillofacial surgery: official journal of the American Association of Oral and Maxillofacial Surgeons 1991, 49(11):1210-1213.

54. Woźniak K, Lipski M, Lichota D, Szyszka-Sommerfeld L: Muscle Fatigue in the Temporal and Masseter Muscles in Patients with Temporomandibular Dysfunction. BioMed Research International 2015, 2015:269734.

55. Garip H, Tufekcioglu S, Kaya E: Changes in the temporomandibular joint disc and temporal and masseter muscles secondary to bruxism in Turkish patients. Saudi Med J 2018, 39(1):81-85.

56. Park KM, Choi E, Kwak EJ, Kim S, Park W, Jeong JS, Kim KD: The relationship between masseter muscle thickness measured by ultrasonography and facial profile in young Korean adults. Imaging Sci Dent 2018, 48(3):213-221.

57. Kim TH, Kim CH: Correlation between mandibular morphology and masticatory muscle thickness in normal occlusion and mandibular prognathism. J Korean Assoc Oral Maxillofac Surg 2020, 46(5):313-320.

58. Korfage JA, Brugman P, Van Eijden TM: Intermuscular and intramuscular differences in myosin heavy chain composition of the human masticatory muscles. J Neurol Sci 2000, 178(2):95-106.

59. Bottinelli R, Canepari M, Pellegrino MA, Reggiani C: Force-velocity properties of human skeletal muscle fibres: myosin heavy chain isoform and temperature dependence. $J$ Physio/ 1996, 495 (Pt 2)(Pt 2):573-586.

60. Weiss A, McDonough D, Wertman B, Acakpo-Satchivi L, Montgomery K, Kucherlapati R, Leinwand L, Krauter K: Organization of human and mouse skeletal myosin heavy chain gene clusters is highly conserved. Proc Natl Acad Sci U S A 1999, 96(6):29582963.

61. Korfage JA, Van Eijden TM: Myosin isoform composition of the human medial and lateral pterygoid muscles. J Dent Res 2000, 79(8):1618-1625.

62. Sullivan DP, Martin PR, Boschen MJ: Psychological Sleep Interventions for Migraine and Tension-Type Headache: A Systematic Review and Meta-Analysis. Sci Rep 2019, 9(1):6411-6411.

63. Tchivileva IE, Ohrbach R, Fillingim RB, Greenspan JD, Maixner W, Slade GD: Temporal change in headache and its contribution to the risk of developing first-onset temporomandibular disorder in the Orofacial Pain: Prospective Evaluation and Risk Assessment (OPPERA) study. Pain 2017, 158(1):120-129.

64. Sterling M, Jull G, Vicenzino B, Kenardy J, Darnell R: Physical and psychological factors predict outcome following whiplash injury. Pain 2005, 114(1-2):141-148.

65. Ohrbach R: Assessment and Further Development of RDC/TMD Axis II Biobehavioral Instruments: A Research Program Progress Report. Journal of oral rehabilitation 2010, 37(10):784-798.

66. Schiffman E, Ohrbach R, Truelove E, Look J, Anderson G, Goulet JP, List T, Svensson P, Gonzalez Y, Lobbezoo F et al: Diagnostic Criteria for Temporomandibular Disorders (DC/TMD) for Clinical and Research Applications: recommendations of the International RDC/TMD Consortium Network* and Orofacial Pain Special Interest Groupt. J Oral Facial Pain Headache 2014, 28(1):6-27.

Page $11 / 20$ 
67. Koolstra JH, van Eijden TM: Dynamics of the human masticatory muscles during a jaw open-close movement. Journal of biomechanics 1997, 30(9):883-889

\section{Tables}

Table 1. Comparison of demographics, and VAS and TMD index scores

\begin{tabular}{|c|c|c|c|}
\hline & $\begin{array}{l}\text { wTMD group } \\
\text { mean } \pm \text { SD or } n(\%)\end{array}$ & $\begin{array}{l}\text { iTMD group } \\
\text { mean } \pm \text { SD or } n(\%)\end{array}$ & \\
\hline & $(n=45)$ & $(n=45)$ & $\mathrm{p}$-value \\
\hline \multicolumn{4}{|l|}{ Demographics } \\
\hline Age, years ${ }^{a}$ & $37.94 \pm 12.27$ & $40.77 \pm 18.02$ & 0.387 \\
\hline Female $^{b}$ & $31(68.9 \%)$ & $33(73.3 \%)$ & 0.816 \\
\hline \multicolumn{4}{|l|}{ Pain characteristics } \\
\hline Symptom duration, days ${ }^{a}$ & $66.27 \pm 58.06$ & $57.78 \pm 48.33$ & 0.453 \\
\hline VAS $^{a}$ & $6.73 \pm 1.84$ & $4.32 \pm 2.80$ & $<0.001 * \star \star$ \\
\hline \multicolumn{4}{|l|}{ TMD indexes } \\
\hline $\mathrm{Pl}^{\mathrm{a}}$ & $0.27 \pm 0.21$ & $0.16 \pm 0.18$ & $0.0086 * *$ \\
\hline Neck $\mathrm{PI}^{\mathrm{a}}$ & $0.45 \pm 0.31$ & $0.27 \pm 0.23$ & $0.003^{* *}$ \\
\hline
\end{tabular}

TMD, temporomandibular disorder; WTMD, the patients had experienced whiplash injury and had no TMD symptoms before the injury; ITMD, the patients who presented with idiopathic/ non-traumatic TMD symptoms without any history of head/neck trauma; VAS, visual analog scale; $\mathrm{PI}$, palpation index; $\mathrm{SD}$, standard deviation.

TMD, temporomandibular disorder; VAS, visual analog scale; PI, palpation index; SD, standard deviation

a: Results were obtained via Mann-Whitney U test, ${ }^{\text {b: }}$ chi-square test (two-sided).

A p-value $<0.05$ was considered significant. *: p-value $<0.05, * \star$ : $p$-value $<0.01, \star \star \star$ : $p$-value $<0.001$. Significant results are in bold text.

Table 2. Distribution of contributing factors 


\begin{tabular}{|c|c|c|c|c|c|}
\hline & \multicolumn{2}{|c|}{ wTMD group } & \multicolumn{3}{|c|}{ ITMD group } \\
\hline & $\mathrm{n}=45$ & Column (\%) & $n=45$ & Column (\%) & p-value \\
\hline \multicolumn{6}{|c|}{ Bruxism ${ }^{a}$} \\
\hline No & 40 & $(88.9)$ & 40 & $(88.9)$ & 1.000 \\
\hline Yes & 5 & $(11.1)$ & 5 & $(11.1)$ & \\
\hline \multicolumn{6}{|c|}{ Clenching $^{\mathrm{b}}$} \\
\hline No & 41 & $(91.1)$ & 33 & $(73.3)$ & $0.026 *$ \\
\hline Yes & 4 & $(8.9)$ & 12 & $(26.7)$ & \\
\hline \multicolumn{6}{|c|}{ Tinnitus $^{a}$} \\
\hline No & 30 & $(66.7)$ & 35 & $(77.8)$ & 0.347 \\
\hline Yes & 15 & (33.3) & 10 & $(22.2)$ & \\
\hline \multicolumn{6}{|c|}{ Headache $^{a}$} \\
\hline No & 13 & $(28.9)$ & 27 & $(60.0)$ & $0.006^{* *}$ \\
\hline Yes & 32 & $(71.1)$ & 18 & $(40.0)$ & \\
\hline \multicolumn{6}{|c|}{ Sleep problem ${ }^{a}$} \\
\hline No & 29 & $(64.4)$ & 19 & $(42.2)$ & $0.028 *$ \\
\hline Yes & 26 & $(57.8)$ & 16 & $(35.6)$ & \\
\hline \multicolumn{6}{|c|}{ Psychological distress ${ }^{a}$} \\
\hline No & 39 & $(86.7)$ & 30 & $(66.7)$ & $0.045^{*}$ \\
\hline Yes & 15 & (33.3) & 6 & (13.3) & \\
\hline
\end{tabular}

TMD, temporomandibular disorder, WTMD, the patients had experienced whiplash injury and had no TMD symptoms before the injury, iTMD; the patients who presented with idiopathic or non-traumatic TMD symptoms without any history of head/neck trauma.

The results were obtained via ${ }^{\text {a }}$ chi-square test (two-sided), and ${ }^{b}$ : Fisher's exact test. A p-value $<0.05$ was considered significant. *: $p$ value $<0.05, * *$ : $p$-value $<0.01$. Significant results are in bold text.

Table 3. Comparison of joint abnormalities from MRI 


\begin{tabular}{|c|c|c|c|c|c|c|}
\hline & & \multicolumn{2}{|c|}{ wTMD group } & \multicolumn{3}{|c|}{ iTMD group } \\
\hline & & $n=45$ & Column (\%) & $n=45$ & Column (\%) & p-value \\
\hline \multirow[t]{2}{*}{ ADDWR } & No & 34 & $(75.6)$ & 32 & $(71.1)$ & 0.812 \\
\hline & Yes & 11 & $(24.4)$ & 13 & $(28.9)$ & \\
\hline \multirow[t]{2}{*}{ ADDWoR } & No & 21 & $(46.7)$ & 32 & $(71.1)$ & $0.032^{*}$ \\
\hline & Yes & 24 & $(53.3)$ & 13 & $(28.9)$ & \\
\hline \multirow[t]{2}{*}{ Disc deformity } & No & 16 & $(35.6)$ & 30 & $(66.7)$ & $0.006 * *$ \\
\hline & Yes & 29 & $(64.4)$ & 15 & (33.3) & \\
\hline \multirow[t]{2}{*}{ Condylar degeneration } & No & 19 & $(42.2)$ & 27 & $(60.0)$ & 0.140 \\
\hline & Yes & 26 & $(57.8)$ & 18 & $(40.0)$ & \\
\hline \multirow[t]{2}{*}{ Effusion } & No & 35 & $(77.8)$ & 36 & $(80.0)$ & 1.000 \\
\hline & Yes & 10 & $(22.2)$ & 9 & $(20.0)$ & \\
\hline
\end{tabular}

TMD, temporomandibular disorder; WTMD, the patients had experienced whiplash injury and had no TMD symptoms before the injury; iTMD, the patients who presented with idiopathic or non-traumatic TMD symptoms without any history of head/neck trauma; ADDWR, anterior disc displacement with reduction; ADDWoR, anterior disc displacement without reduction

The results were obtained via the chi-square test (two-sided). A p-value $<0.05$ was considered significant. $*$ : $p$-value $<0.05$, $* *$ : p-value $<$ 0.01 . Significant results are in bold text.

Table 4. Comparison of masticatory muscle abnormalities from MRI

\begin{tabular}{|c|c|c|c|c|c|c|c|}
\hline & & & \multicolumn{2}{|c|}{ wTMD group } & \multicolumn{2}{|c|}{ iTMD group } & \multirow[b]{2}{*}{ p-value } \\
\hline & & & $n=45$ & Column (\%) & $\mathrm{n}=45$ & Column (\%) & \\
\hline \multirow[t]{4}{*}{ Masseter muscle ${ }^{b}$} & vc & No & 45 & $(100.0)$ & 45 & $(100.0)$ & . \\
\hline & & Yes & 0 & $(0.0)$ & 0 & $(0.0)$ & \\
\hline & SC & No & 45 & $(100.0)$ & 45 & $(100.0)$ & \\
\hline & & Yes & 0 & $(0.0)$ & 0 & $(0.0)$ & \\
\hline \multirow[t]{4}{*}{ Temporalis muscle ${ }^{\text {b }}$} & vc & No & 44 & $(97.8)$ & 44 & $(97.8)$ & 1.000 \\
\hline & & Yes & 1 & $(2.2)$ & 1 & $(2.2)$ & \\
\hline & SC & No & 44 & $(97.8)$ & 44 & $(97.8)$ & 1.000 \\
\hline & & Yes & 1 & $(2.2)$ & 1 & $(2.2)$ & \\
\hline \multirow[t]{4}{*}{ LPM $^{\text {a }}$} & vc & No & 19 & $(42.2)$ & 37 & $(82.2)$ & $<.0001 * *$ \\
\hline & & Yes & 26 & $(57.8)$ & 8 & $(17.8)$ & \\
\hline & $\mathrm{SC}$ & No & 26 & $(57.8)$ & 38 & $(84.4)$ & 0.010 ** \\
\hline & & Yes & 19 & $(42.2)$ & 7 & $(15.6)$ & \\
\hline \multirow[t]{4}{*}{ MPM $^{b}$} & vc & No & 45 & $(100.0)$ & 43 & $(95.6)$ & 0.494 \\
\hline & & Yes & 0 & $(0.0)$ & 2 & $(4.4)$ & \\
\hline & SC & No & 45 & $(100.0)$ & 43 & $(95.6)$ & 0.494 \\
\hline & & Yes & 0 & $(0.0)$ & 2 & (4.4) & \\
\hline
\end{tabular}


TMD, temporomandibular disorder; WTMD, the patients had experienced whiplash injury and had no TMD symptoms before the injury; iTMD, the patients who presented with idiopathic/ non-traumatic TMD symptoms without any history of head/neck trauma; LPM, lateral pterygoid muscle; MPM, medial pterygoid muscle; VC, volume change; SC, signal change.

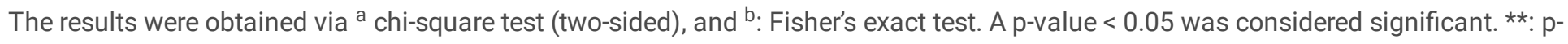
value $<0.01, \star \star *$ : $p$-value $<0.001$. Significant results are in bold text.

Table 5. Comparison of muscle tenderness upon palpation test

\begin{tabular}{|c|c|c|c|c|c|}
\hline & \multicolumn{2}{|c|}{ wTMD group } & \multicolumn{3}{|c|}{ iTMD group } \\
\hline & $\mathrm{n}=45$ & Column (\%) & $\mathrm{n}=45$ & Column (\%) & p-value \\
\hline \multicolumn{6}{|c|}{ Masseter muscle tenderness ${ }^{a}$} \\
\hline No & 13 & $(28.9)$ & 16 & $(35.6)$ & 0.652 \\
\hline Yes & 32 & $(71.1)$ & 29 & $(64.4)$ & \\
\hline \multicolumn{6}{|c|}{ Temporalis muscle tenderness ${ }^{a}$} \\
\hline No & 18 & $(40.0)$ & 29 & $(64.4)$ & $0.034^{*}$ \\
\hline Yes & 27 & $(60.0)$ & 16 & $(35.6)$ & \\
\hline \multicolumn{6}{|c|}{ LPM tenderness $^{b}$} \\
\hline No & 35 & $(77.8)$ & 44 & $(97.8)$ & $0.007 * *$ \\
\hline Yes & 10 & $(22.2)$ & 1 & $(2.2)$ & \\
\hline \multicolumn{6}{|c|}{ MPM tenderness $^{b}$} \\
\hline No & 38 & $(84.4)$ & 45 & $(100.0)$ & $0.012^{*}$ \\
\hline Yes & 7 & $(15.6)$ & 0 & $(0.0)$ & \\
\hline
\end{tabular}

TMD, temporomandibular disorder; WTMD, the patients had experienced whiplash injury and had no TMD symptoms before the injury; iTMD, the patients who presented with idiopathic/ non-traumatic TMD symptoms without any history of head/neck trauma; LPM, lateral pterygoid muscle; MPM, medial pterygoid muscle.

The results were obtained via ${ }^{\text {a }}$ chi-square test (two-sided), and ${ }^{\mathrm{b}}$ : Fisher's exact test. A p-value $<0.05$ was considered significant. *: $p$ value $<0.05$, $*$ : $p$-value $<0.01$. Significant results are in bold text.

Table 6. Associated abnormal MRI findings with increasing TMD index 


\begin{tabular}{|c|c|c|c|c|c|c|c|c|c|c|c|c|}
\hline & \multicolumn{6}{|l|}{ wTMD } & \multicolumn{6}{|l|}{ iTMD } \\
\hline & \multicolumn{2}{|l|}{ VAS } & \multicolumn{2}{|l|}{$\mathrm{PI}$} & \multicolumn{2}{|l|}{ Neck PI } & \multicolumn{2}{|l|}{ VAS } & \multicolumn{2}{|l|}{ PI } & \multicolumn{2}{|l|}{ Neck PI } \\
\hline & $r$ & $\begin{array}{l}\mathrm{p} \text { - } \\
\text { value }\end{array}$ & $r$ & $\begin{array}{l}\mathrm{p}- \\
\text { value }\end{array}$ & $r$ & $\begin{array}{l}\mathrm{p} \text { - } \\
\text { value }\end{array}$ & $r$ & $\begin{array}{l}\mathrm{p} \text { - } \\
\text { value }\end{array}$ & $r$ & $\begin{array}{l}\mathrm{p} \text { - } \\
\text { value }\end{array}$ & $r$ & $\begin{array}{l}\mathrm{p}- \\
\text { value }\end{array}$ \\
\hline \multicolumn{13}{|l|}{$T M D$ index } \\
\hline $\mathrm{PI}$ & 0.174 & 0.252 & 1.000 & & $.866^{\star \star *}$ & $<0.001$ & $.300^{*}$ & 0.045 & 1.000 & & $.764^{* \star *}$ & $<0.001$ \\
\hline Neck PI & 0.081 & 0.597 & $.866^{\star \star *}$ & $<0.001$ & 1.000 & & $.301^{*}$ & 0.044 & $.764^{\star \star *}$ & $<0.001$ & 1.000 & \\
\hline \multicolumn{13}{|c|}{ Abnormality of masticatory muscle } \\
\hline Temp. VC & -0.124 & 0.416 & -0.180 & 0.236 & -0.006 & 0.970 & -0.029 & 0.849 & -0.059 & 0.703 & -0.035 & 0.820 \\
\hline Temp. SC & -0.124 & 0.416 & -0.180 & 0.236 & -0.006 & 0.970 & -0.029 & 0.849 & -0.059 & 0.703 & -0.035 & 0.820 \\
\hline LPM VC & -0.254 & 0.092 & -0.089 & 0.563 & 0.094 & 0.540 & -0.135 & 0.377 & -0.210 & 0.167 & -0.092 & 0.547 \\
\hline LPM SC & $.346^{*}$ & 0.020 & 0.069 & 0.650 & 0.229 & 0.130 & -0.185 & 0.224 & 0.061 & 0.689 & -0.171 & 0.262 \\
\hline MPM VC & - & - & - & - & - & - & -0.217 & 0.153 & -0.293 & 0.051 & -0.064 & 0.674 \\
\hline MPM SC & - & - & - & - & - & - & -0.217 & 0.153 & -0.293 & 0.051 & -0.064 & 0.674 \\
\hline \multicolumn{13}{|c|}{ Abnormality of TMJ } \\
\hline ADDWR & -0.043 & 0.781 & 0.208 & 0.171 & 0.130 & 0.395 & 0.064 & 0.674 & -0.202 & 0.184 & -0.178 & 0.241 \\
\hline ADDWoR & 0.040 & 0.793 & -0.158 & 0.299 & -0.084 & 0.582 & $.325^{*}$ & 0.029 & 0.124 & 0.418 & 0.169 & 0.268 \\
\hline $\begin{array}{l}\text { Disc } \\
\text { deformity }\end{array}$ & -0.175 & 0.251 & 0.000 & 1.000 & -0.029 & 0.852 & 0.200 & 0.187 & -0.082 & 0.591 & -0.007 & 0.962 \\
\hline $\begin{array}{l}\text { Condylar } \\
\text { degeneration }\end{array}$ & -0.053 & 0.730 & -0.089 & 0.563 & -0.144 & 0.345 & $.297^{\star}$ & 0.047 & -0.070 & 0.646 & 0.098 & 0.521 \\
\hline Effusion & 0.021 & 0.891 & -0.274 & 0.068 & -0.134 & 0.379 & 0.180 & 0.236 & 0.181 & 0.234 & 0.067 & 0.664 \\
\hline
\end{tabular}

TMD, temporomandibular disorder; wTMD, the patients had experienced whiplash injury and had no TMD symptoms before the injury; iTMD, the patients who presented with idiopathic/ non-traumatic TMD symptoms without any history of head/neck trauma; $\mathrm{PI}$, palpation index; Temp, temporalis muscle; LPM, lateral pterygoid muscle; MPM, medial pterygoid muscle; VC, volume change; SC, signal change; ADDWR, anterior disc displacement with reduction; ADDWoR, anterior disc displacement without reduction. Volume and signal changes of the masseter muscle were not observed at all, so the correlation coefficient related to this muscle could not be determined.

The results were obtained via Spearman's correlation analysis. A p-value $<0.05$ was considered significant. $\star \star$ : $p$-value $<0.01$, $\star \star \star *: p-$ value $<0.001$. Significant results are in bold text.

\section{Figures}



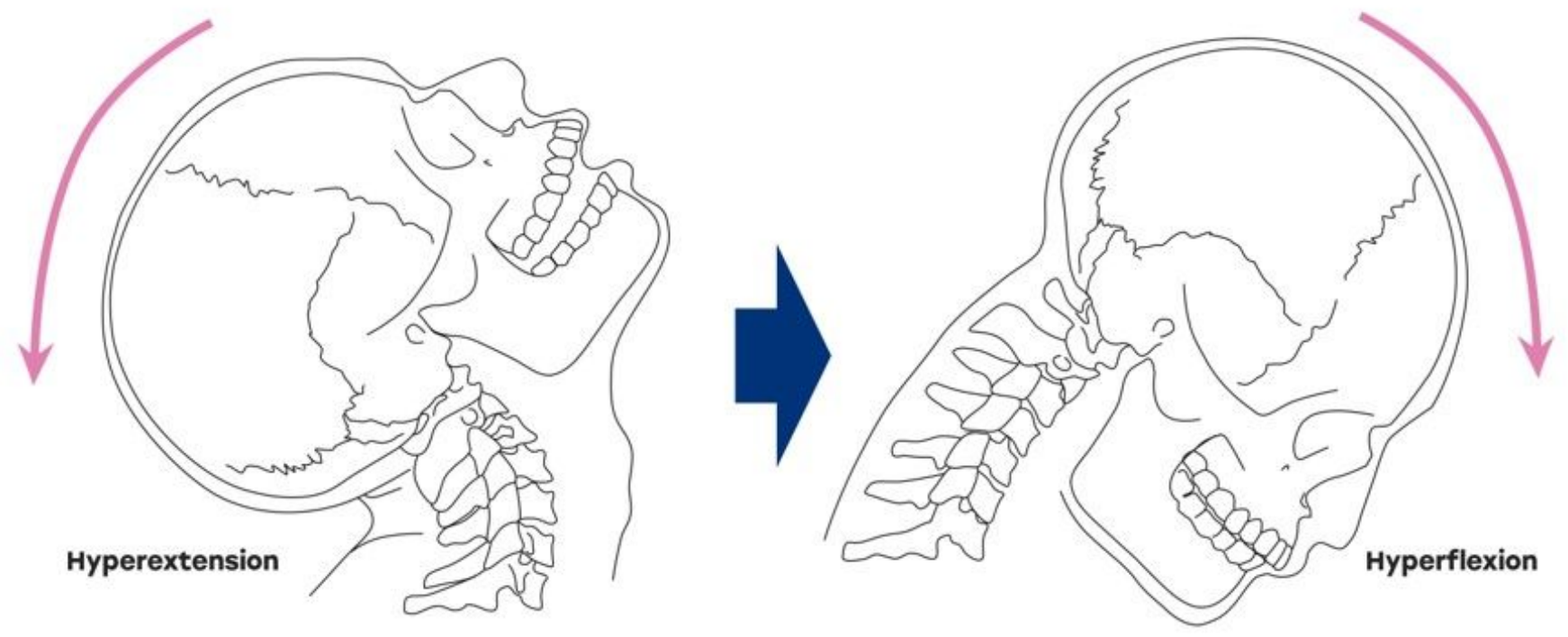

\section{Figure 1}

Dynamic mechanism of whiplash injury with hyperextension-hyperflexion Whiplash injury refers to a macrotrauma that occurs with a sudden hyperextension followed by hyperflexion which can initiate or aggravate the TMD symptoms.

(a)

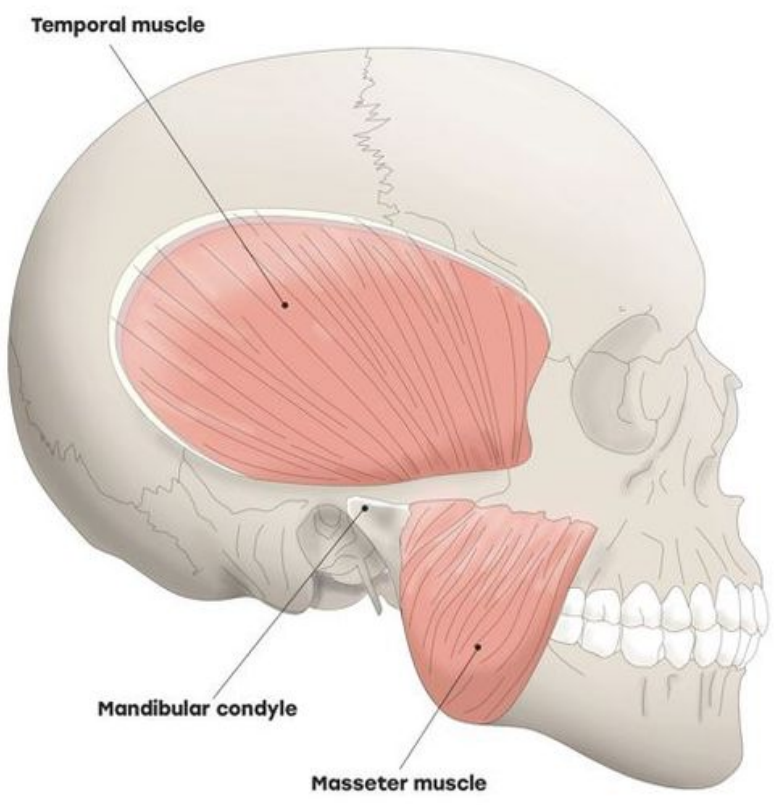

(b)

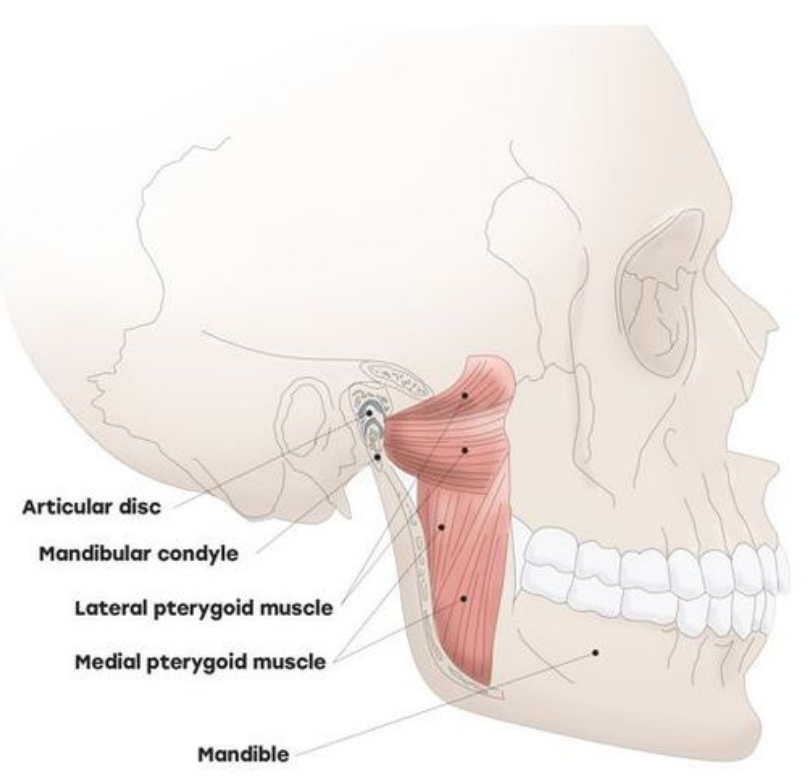




\section{Figure 2}

Four main masticatory muscles and TMJ TMJ and four major masticatory muscles including (a) temporalis muscle, masseter muscle, (b) lateral pterygoid muscle, and medial pterygoid muscle.

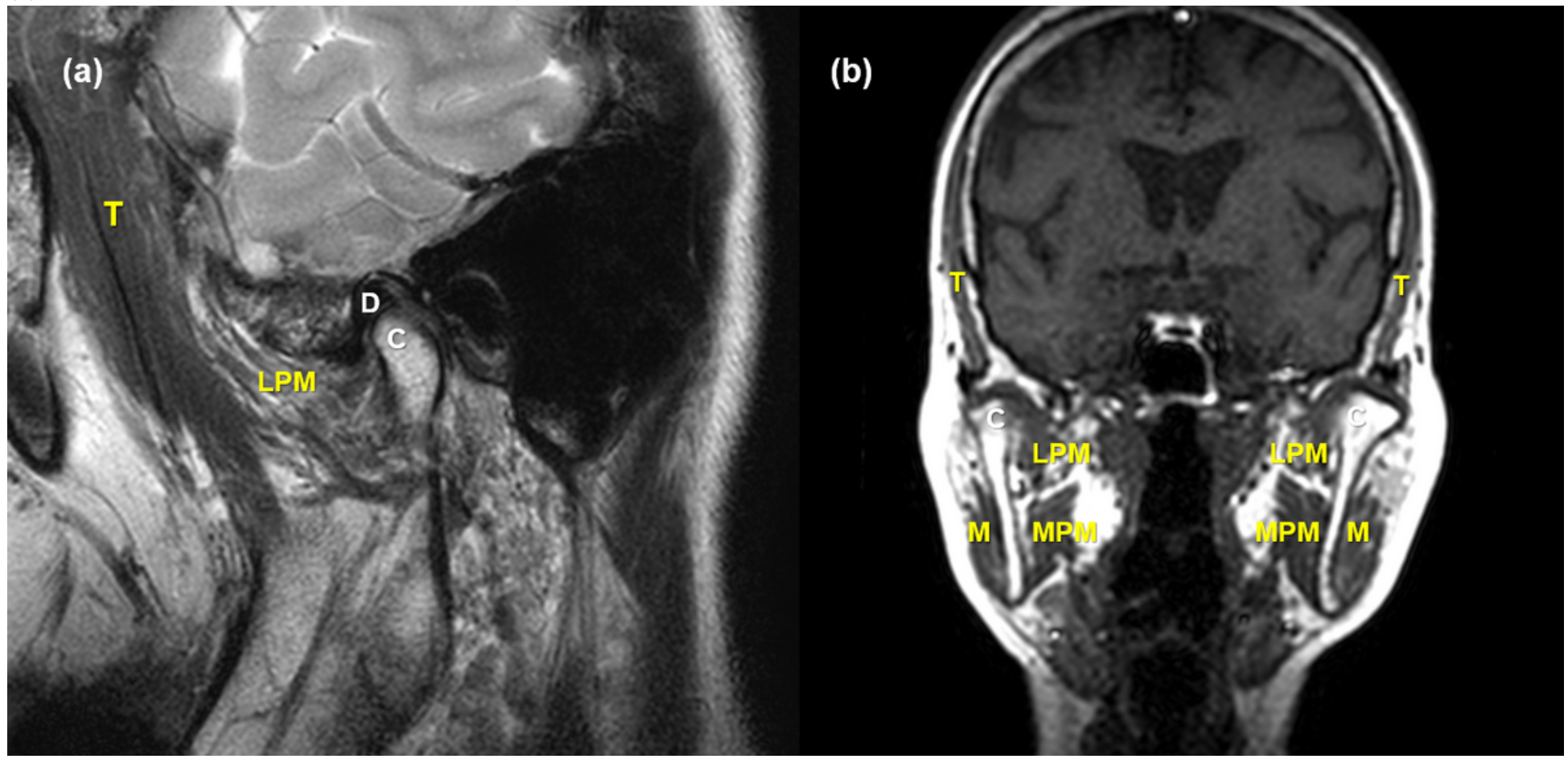

\section{Figure 3}

Representative magnetic resonance (MR) images of masticatory muscle and TMJ T2-weighted (a) sagittal and (b) coronal MR images represents the location of four main masticatory muscles, articular disc, and mandibular condyle. $\mathrm{M}$, masseter muscle; T, temporalis muscle; LPM, lateral pterygoid muscle; MPM, medial pterygoid muscle; C, condyle; D, articular disc.

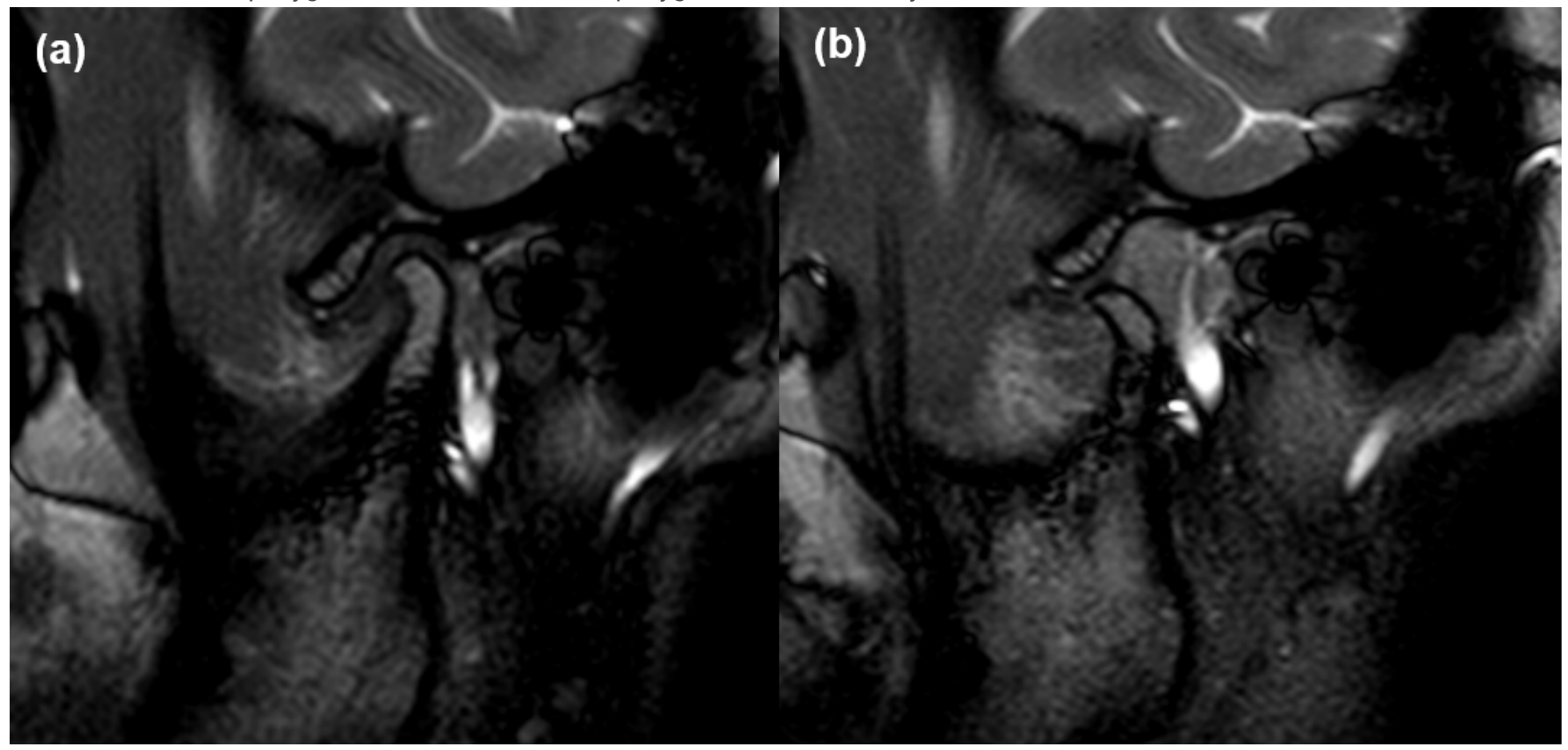

Figure 4 
Disc displacement in TMJ on magnetic resonance images (a) Anteriorly displaced articular disc in the oblique sagittal T1-weighted image obtained in the closed-mouth position, and (b) anterior disc displacement without reduction where the relationship between disccondyle is not recaptured in the open-mouth view.

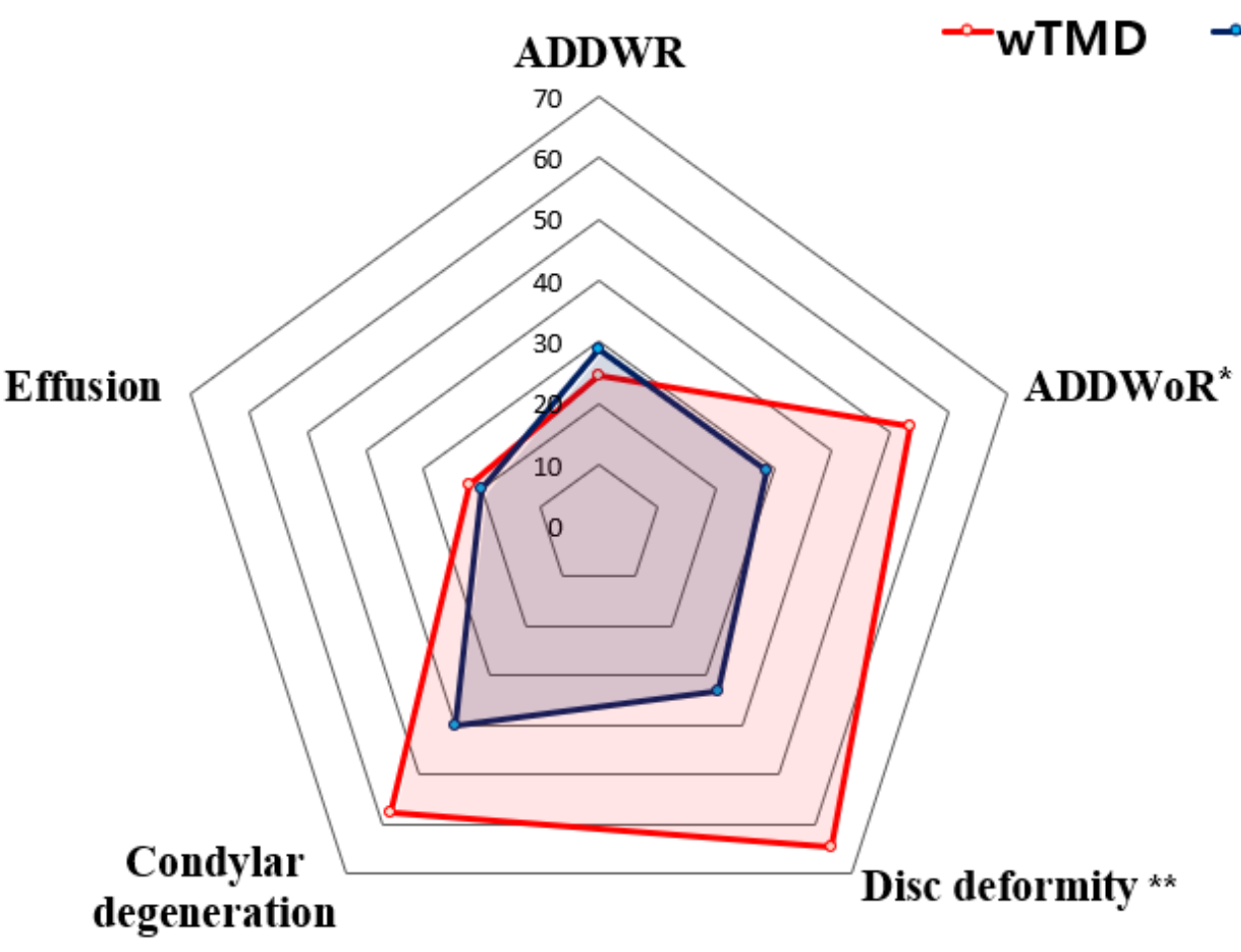

Figure 5

Changes in TMJ from magnetic resonance image A p-value $<0.05$ was considered significant. *: $p$-value $<0.05, * *$ : $p$-value $<0.01$. ADDWR, anterior disc displacement with reduction; ADDWoR, anterior disc displacement without reduction.

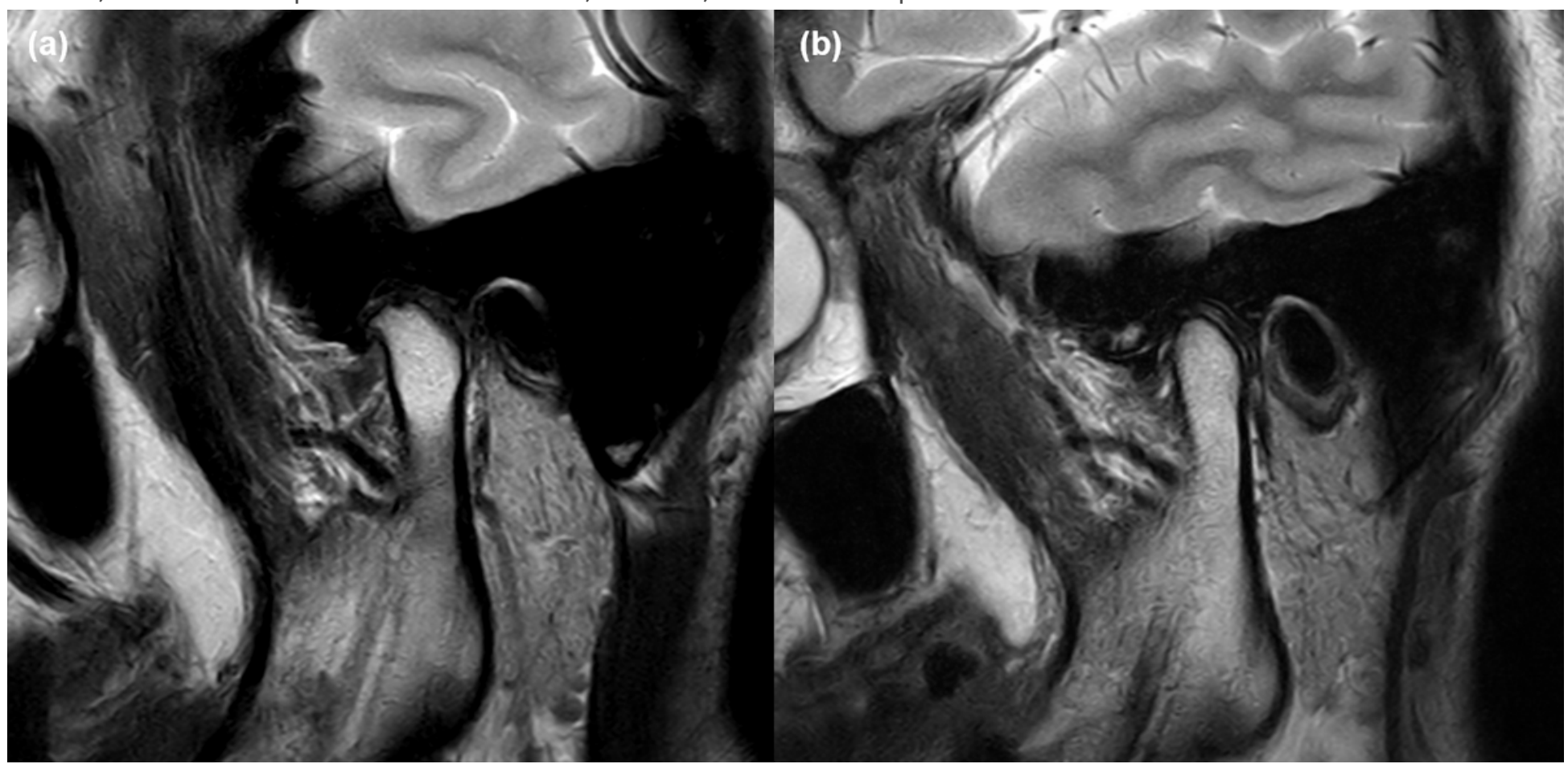




\section{Figure 6}

Representative volume changes (VCs) and signal changes (SCs) in the lateral pterygoid muscle (LPM) (a) Proton density-weighted magnetic resonance image obtained in the closed-mouth position showing fatty replacement and atrophic change in the LPM. (b) Both the VCs and SCs in the LPM were observed with disc displacement in the closed-mouth position.

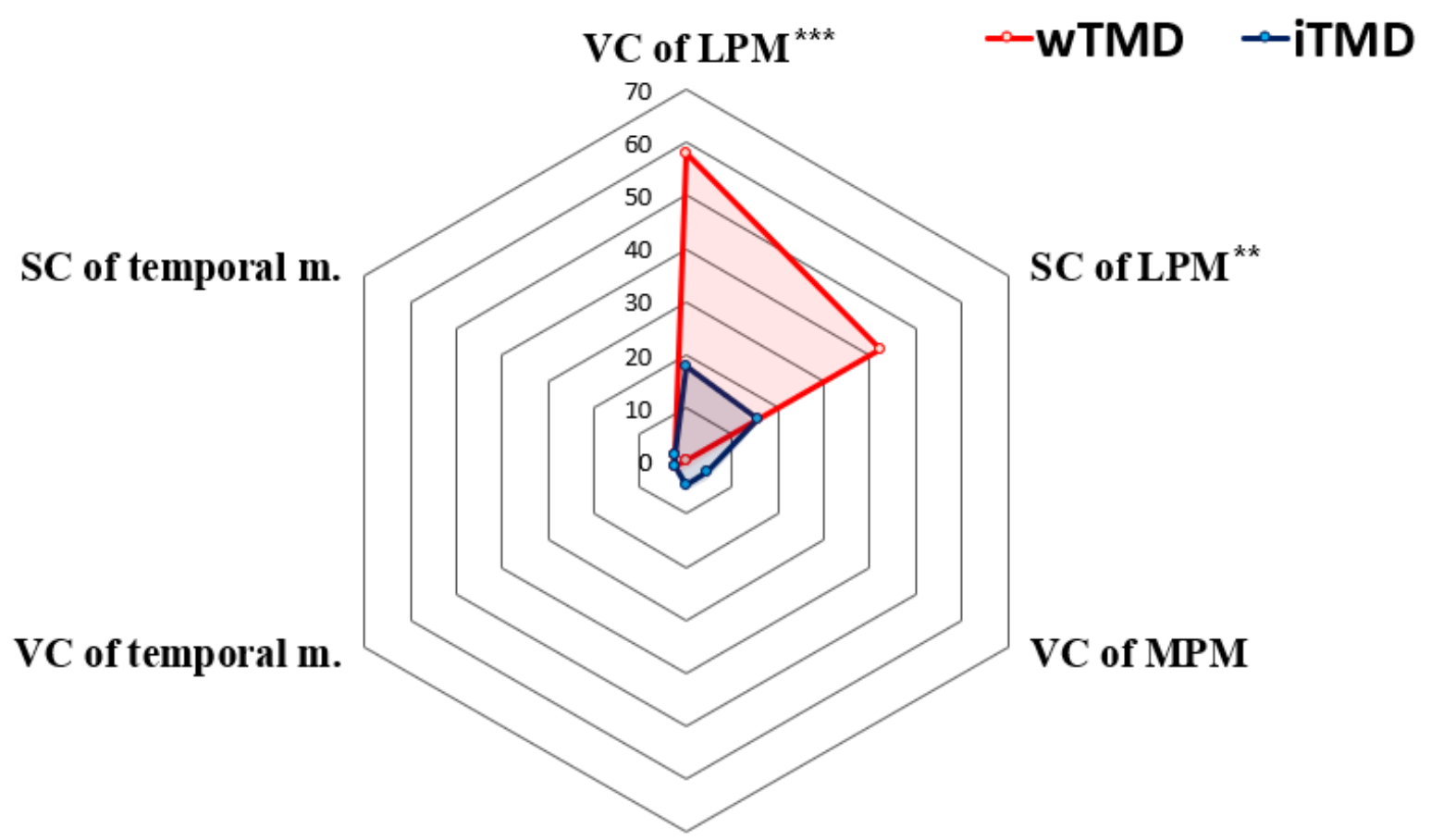

SC of MPM

\section{Figure 7}

Changes in masticatory muscle abnormalities from magnetic resonance image A p-value $<0.05$ was considered significant. *: p-value < 0.05 , **: p-value $<0.01$. VC, volume change; SC, signal change; LPM, lateral pterygoid muscle; MPM, medial pterygoid muscle. 